\title{
Utility of thromboelastography and/or thromboelastometry in adults with sepsis: a systematic review
}

\author{
Marcella C Müller ${ }^{1 *}$, Joost CM Meijers², Margreeth B Vroom and Nicole P Juffermans ${ }^{1}$
}

\begin{abstract}
Introduction: Coagulation abnormalities are frequent in sepsis. Conventional coagulation assays, however, have several limitations. A surge of interest exists in the use of point-of-care tests to diagnose hypo- and hypercoagulability in sepsis.

We performed a systematic review of available literature to establish the value of rotational thromboelastography (TEG) and thromboelastometry (ROTEM) compared with standard coagulation tests to detect hyper- or hypocoagulability in sepsis patients. Furthermore, we assessed the value of TEG/ROTEM to identify sepsis patients likely to benefit from therapies that interfere with the coagulation system.

Methods: MEDLINE, EMBASE, and the Cochrane Library were searched from 1 January 1980 to 31 December 2012. The search was limited to adults, and language was limited to English. Reference lists of retrieved articles were hand-searched for additional studies. Ongoing trials were searched on www.controlled-trials.com and www.clinicaltrials.gov. Studies addressing TEG/ROTEM measurements in adult patients with sepsis admitted to the ICU were considered eligible.

Results: Of 680 screened articles, 18 studies were included, of which two were randomized controlled trials, and 16 were observational cohort studies. In patients with sepsis, results show both hyper- and hypocoagulability, as well as TEG/ROTEM values that fell within reference values. Both hyper- and hypocoagulability were to some extent associated with diffuse intravascular coagulation. Compared with conventional coagulation tests, TEG/ROTEM can detect impaired fibrinolysis, which can possibly help to discriminate between sepsis and systemic inflammatory response syndrome (SIRS). A hypocoagulable profile is associated with increased mortality. The value of TEG/ROTEM to identify patients with sepsis who could possibly benefit from therapies interfering with the coagulation system could not be assessed, because studies addressing this topic were limited.
\end{abstract}

Conclusion: TEG/ROTEM could be a promising tool in diagnosing alterations in coagulation in sepsis. Further research on the value of TEG/ROTEM in these patients is warranted. Given that coagulopathy is a dynamic process, sequential measurements are needed to understand the coagulation patterns in sepsis, as can be detected by TEG/ROTEM.

\section{Introduction}

Coagulopathy is highly prevalent in sepsis patients and is associated with increased mortality [1]. Coagulopathy results from an imbalance between activation of coagulation and impaired inhibition of coagulation and fibrinolysis. The disturbance between components of the coagulation

\footnotetext{
* Correspondence: m.c.muller@amc.uva.nl

'Department of Intensive Care Medicine and Laboratory of Experimental Intensive Care and Anesthesiology (L.E.I.C.A.), Academic Medical Center, Room G3-220, Meibergdreef 9, 1105AZ, Amsterdam, The Netherlands Full list of author information is available at the end of the article
}

system leads to a variable clinical picture, ranging from an increased bleeding tendency due to consumption of coagulation factors and platelets, to hypercoagulopathy with disseminated intravascular coagulation (DIC) and (micro-) vascular thrombosis.

Assessment of coagulation status in these patients is complex. Global coagulation tests activating partial thromboplastin time (APTT) and prothrombin time (PT) are used clinically. However, their ability to reflect in vivo hypocoagulability accurately is questioned [2]. Also, APTT and PT reflect only a part of the coagulation system and do not

\section{Biomed Central}


provide information on the full balance between coagulation and anticoagulation. Activation of coagulation can be assessed by thrombin generation, but this test is not widely available. Impaired function of the anticoagulant system can be diagnosed by measuring plasma levels of naturally occurring anticoagulant factors antithrombin (AT), protein $\mathrm{C}$, protein $\mathrm{S}$, and tissue factor pathway inhibitor (TFPI). However, these are not readily available for clinical use. The same applies to markers of the activity of the fibrinolytic system [2]. Although activation of the fibrinolytic system can be detected by increased levels of D-dimers and other fibrin-degradation products, specificity is limited [2].

Rotational thromboelastography (TEG) and thromboelastometry (ROTEM) are point-of-care tests, which evaluate whole-clot formation and dissolution. The thromboelastogram arises through movement of the cup (TEG) or the pin (ROTEM). As fibrin forms between the cup and the pin, this movement is influenced and converted to a trace reflecting different phases of the clotting process. Major parameters are reaction time $(\mathrm{R})$ or clotting time $(\mathrm{CT})$, which is the period from the initiation of the test until the beginning of clot formation (Figure 1). K-time or clot formation time (CFT) is the period from the start of the clot formation until the curve reaches an amplitude of $20 \mathrm{~mm}$. Kinetics of fibrin formation and cross-linking are expressed by the $\alpha$-angle, which is the angle between the baseline and the tangent to the TEG/ROTEM curve amplitude. Clot strength is represented by the maximal amplitude of the trace. The degree of fibrinolysis is reflected by the difference between the maximal amplitude and the amplitude measured after 30 and/or 60 minutes (Figure 1). To describe these viscoelastic changes, both systems have their own terminology (Table 1).

The technique was developed in the 1940s, but clinical application has been limited. However, technical developments have led to standardization and improved reproducibility of the method $[3,4]$. TEG/ROTEM may facilitate diagnosis of clotting abnormalities in sepsis, including hypercoagulable states such as DIC. Other potential advantages could be a more tailor-made administration of therapies that interfere with the coagulation system [5-8]. These tests also may improve prognostication of sepsis $[9,10]$.

The main research questions for this systemic review were as follows. Can TEG/ROTEM detect sepsis-induced coagulopathy? Is TEG/ROTEM of additional value compared with standard coagulation tests to detect hyper- or hypocoagulability in sepsis patients? Can TEG/ROTEM help to identify sepsis patients likely to benefit from therapies that interfere with the coagulation system (for example, activated protein $\mathrm{C}$, antithrombin, heparin)? We defined our population as critically ill adults with sepsis and TEG/ROTEM as the intervention. Standard coagulation tests, including APTT, PT, INR, and ISTH DIC score, functioned as comparisons. Outcomes of interest were the detection of a hyper- or hypocoagulable state in these patients and the identification of patients likely to benefit from therapies affecting the coagulation system.

\section{Materials and methods}

\section{Data sources}

An electronic search was conducted in MEDLINE, EMBASE, and the Cochrane Library. In addition, we searched for ongoing trials on www.controlled-trials. com and www.clinicaltrials.gov. We hand-searched the reference lists of retrieved articles, reviews, and editorials for additional studies. Language was limited to articles written in English and published from 1 January 1980 to 31 December 2012. We did not register our protocol.

\section{Study selection}

Two authors (MCM and NPJ) performed the literature search and selected the relevant articles for inclusion.

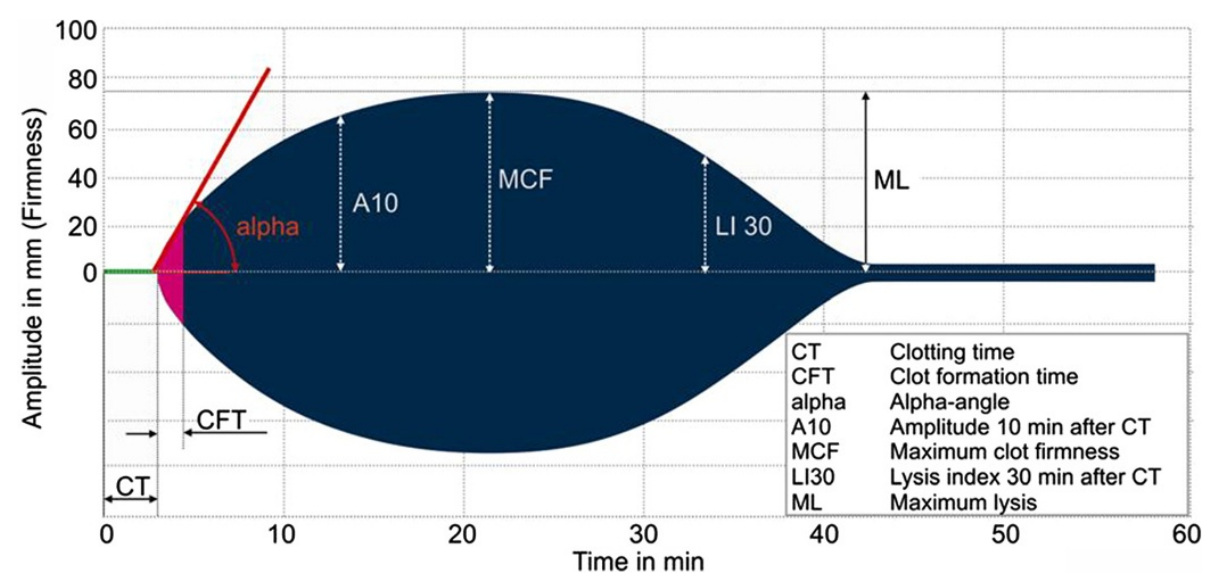

Figure 1 ROTEM trace with major parameters. Reference: www.rotem.de. 
Table 1 Parameters displayed on TEG and ROTEM

\begin{tabular}{lll}
\hline & TEG & ROTEM \\
\hline $\begin{array}{l}\text { Time to initial fibrin formation } \\
\text { (to 2-mm amplitude) }\end{array}$ & $R$ & CT \\
$\begin{array}{l}\text { Clot strengthening, rapidity of } \\
\text { fibrin buildup }\end{array}$ & $K$ & CFT \\
$\begin{array}{l}\text { Clot strength, represents maximum } \\
\begin{array}{l}\text { dynamics of fibrin and platelet } \\
\text { bonding }\end{array}\end{array}$ & MA & a \\
$\begin{array}{l}\text { Clot breakdown, fibrinolysis at } \\
\text { fixed time }\end{array}$ & CL30, CL60 & LI30, LI45, LI60 \\
\hline
\end{tabular}

Reference: www.rotem.de and www.haemoscope.com.

Differences were resolved in consensus meetings. Predefined eligibility criteria were used. Studies were included if TEG/ROTEM measurements were performed in adult patients with sepsis admitted to the ICU. Randomized controlled trials, prospective and retrospective cohorts, and case series were all eligible for inclusion. Reviews, correspondences, case reports, expert opinions, and editorials were excluded. We also excluded all studies conducted outside the ICU or that involved subjects younger than 18 years.

\section{Data-collection process}

Two of the authors (MCM and NPJ) independently extracted the data by using a predefined extraction sheet. Discrepancies were resolved in a consensus meeting. If agreement could not be reached, a third author was consulted (MBV) to resolve disagreement. The extracted data were general methodologic characteristics, setting, characteristics of the study population, used test (ROTEM or TEG), timing of thromboelastography, possible comparison of thromboelastography results with a reference test, administration of therapies interfering with the coagulation system, and main outcomes. Furthermore, possible limitations of each study were listed. No assumptions or simplifications were made.

\section{Assessment of methodologic quality}

We used the QUADAS-2 checklist to assess the quality of diagnostic studies $[11,12]$. Studies were assessed for the risk of bias in patient selection, conduct and interpretation of TEG/ROTEM, use and interpretation of a reference standard, and patient flow. For all research questions, methodologic aspects, including the use of a comparison of TEG/ROTEM measurement, the individual studies were assessed. Furthermore, studies were judged with respect to patient population and selection (use of definition of sepsis). Details on how TEG/ROTEM and reference tests were conducted and interpreted (for example, timing of the tests, blinded interpretation) were assessed. Subsequently, quality of evidence was judged and described in accordance with the GRADE approach (high, moderate, low, and very low). Rating of quality of evidence was based on trial design (for example, randomized clinical trial or not), risk of bias and imprecision (for example, patient selection and patient flow, method of conduct and interpretation of TEG/ROTEM, and reference test results). We verified whether results of the retrieved trials and abstracts had been published.

\section{Definitions}

Hypocoagulability can be defined as prolonged $\mathrm{CT} / R$ and CFT/K times and/or decreased MCF/MA and alpha angle [4]. Conversely, a hypercoagulable state can be detected by shortened reaction times (CT/R and/or CFT/K) and enhanced clot formation, expressed as increased alpha and/or high maximal amplitude (MCF/MA). However, no universal definitions of hypo- and hypercoagulability assessed by TEG/ROTEM exist.

\section{Results}

\section{Study selection}

Of 680 screened articles, we included 18 studies (Table 2). An overview of the search is presented in Figure 2. Twenty-six studies were excluded because of inappropriate patient population $(N=21$ [13-33]), no report of TEG/ ROTEM data $(N=6[31,32,34-37])$, and one conference poster [38].

\section{Study characteristics}

We included two randomized controlled trials $[39,40]$ and 16 observational studies $[9,10,41-54]$. Of the observational studies, 14 were prospective and one abstract [45] and one article [42] did not state whether the study was prospective or retrospective. Of the included studies, $11[9,10,41,43,44,48-51,53,54]$ used the sepsis and SIRS criteria defined by the Society of Critical Care Medicine Consensus Conference [55]. Seven studies used TEG $[10,39,40,42,49,51,53]$, and 11 used ROTEM $[9,41,43-48,50,52,54]$.

\section{Risk of bias}

The risk of bias within studies is summarized in Table 3 . Quality assessment revealed that risk of bias of patient selection was low. However, included studies were heterogeneous regarding conduction and interpretation of TEG/ROTEM, and no studies reported whether results of TEG/ROTEM were interpreted with or without knowledge of the used reference test, which leaves the possibility for interpretation bias. However, applicability concerns of the chosen reference tests are low.

In addition to individual sources of bias related to design and methods, we identified the lack of information about the conduct and interpretation of the TEG/ ROTEM test and results as the most important source of bias across all studies (Table 3). We verified whether 


\section{Table 2 Studies assessing TEG/ROTEM in sepsis}

\begin{tabular}{|c|c|c|c|c|c|c|}
\hline Author, year & Type of study & Population $(N)$ & $\begin{array}{l}\text { ROTEM } \\
\text { or TEG }\end{array}$ & $\begin{array}{l}\text { Timing of } \\
\text { measurement }\end{array}$ & Comparison & Main ROTEM/TEG findings \\
\hline Gonano [40] & $\begin{array}{l}\text { Subanalysis of randomized } \\
\text { controlled trial }\end{array}$ & Severe sepsis $(n=33)$ & TEG & $\begin{array}{l}\text { At diagnosis and daily } \\
\text { thereafter. }\end{array}$ & PT, APTT, AT & $\begin{array}{l}\text { All patients were hypercoagulable (shortened } \\
R \text { and } C T \text {, increased a and MA). Antithrombin } \\
\text { treatment did not affect TEG values. }\end{array}$ \\
\hline $\begin{array}{l}\text { Raineri (abstract) } \\
\text { [39] }\end{array}$ & $\begin{array}{l}\text { Randomized controlled } \\
\text { trial }\end{array}$ & $\begin{array}{l}\text { Severe sepsis and septic } \\
\text { shock }(n=16)\end{array}$ & TEG & $\begin{array}{l}\text { Daily for } 2 \text { weeks and } \\
\text { day } 17,20,23,28\end{array}$ & PAl-1 & $\begin{array}{l}\text { In patients without tight glycemic control (TGC), } \\
\text { fibrinolysis was decreased (increased lysis index } \\
\text { and increased PAI-1), compared with sepsis } \\
\text { patients not treated with TGC. }\end{array}$ \\
\hline Collins [43] & Prospective observational & $\begin{array}{l}\text { Sepsis }(n=38) \text {, healthy } \\
\text { controls }(n=32)\end{array}$ & ROTEM & Not stated & $\begin{array}{l}\text { PT, APTT fibrinogen, } \\
\text { factor levels }\end{array}$ & $\begin{array}{l}\text { In sepsis, there was delayed activation of } \\
\text { hemostasis, once activated clot formation } \\
\text { was exaggerated (increased MCF, a angle, area } \\
\text { under clot firmness curve) }\end{array}$ \\
\hline $\begin{array}{l}\text { Chiari (abstract) } \\
{[47]}\end{array}$ & Prospective observational & Severe sepsis $(n=15)$ & ROTEM & $\begin{array}{l}\text { Before and first day of } \\
\text { treatment with activated } \\
\text { protein C }\end{array}$ & APTT, PT & $\begin{array}{l}\text { Only CT significantly increased with activated } \\
\text { protein } C \text { treatment }\end{array}$ \\
\hline Daudel [44] & Prospective cohort & Sepsis $(n=30)$ & ROTEM & $\begin{array}{l}0-48 \text { hours after diagnosis } \\
\text { and at discharge }\end{array}$ & $\begin{array}{l}\text { INR, APTT, fibrinogen, } \\
\text { individual factors }\end{array}$ & $\begin{array}{l}\text { All parameters within reference values. Patients } \\
\text { with SOFA }>10 \text { had increased coagulation } \\
\text { (reduced MCF and alpha and increased CFT). }\end{array}$ \\
\hline $\begin{array}{l}\text { Schmittinger } \\
\text { (abstract) [46] }\end{array}$ & Prospective observational & $\begin{array}{l}\text { Severe sepsis }(n=49) \text {, } \\
\text { postoperative } \\
\text { SIRS }(n=27)\end{array}$ & ROTEM & $\begin{array}{l}\text { Day } 1,4,7 \text { after } \\
\text { admission }\end{array}$ & None & $\begin{array}{l}\text { All parameters within reference values. Mortality } \\
58.3 \% \text { in patients with signs of hypocoagulation } \\
\text { vs. } 9.1 \% \text { in those with signs of hypercoagulability. }\end{array}$ \\
\hline Sivula [41] & Prospective observational & $\begin{array}{l}\text { Severe sepsis }(n=28) \text {, } \\
\text { healthy controls }(n=8)\end{array}$ & ROTEM & Day 1 & $\begin{array}{l}\text { APTT, AT, D-dimer, } \\
\text { fibrinogen }\end{array}$ & $\begin{array}{l}\text { Only sepsis patients with DIC were hypocoagulable } \\
\text { compared to healthy controls. CFT, alpha } \\
\text { and MCF discriminated well between DIC and } \\
\text { non- DIC. Decreased fibrinolysis in all sepsis } \\
\text { patients versus controls. }\end{array}$ \\
\hline Adamzik [50] & Prospective observational & $\begin{array}{l}\text { Sepsis }(n=56) \text {, postoperative } \\
\text { controls }(n=52)\end{array}$ & ROTEM & $\begin{array}{l}\text { Within } 24 \text { hours of } \\
\text { sepsis diagnosis }\end{array}$ & $\begin{array}{l}\text { Procalcitonin, } \\
\text { IL-6, CRP }\end{array}$ & $\begin{array}{l}\text { Increased lysis index in sepsis compared to } \\
\text { postoperative controls }(97 \pm 0.3 \% \text { vs. } 92 \pm 0.5 \% \text {, } \\
p<0.001) \text {. CFT, alpha and MCF did not differ } \\
\text { between groups. Lysis index had best accuracy for } \\
\text { diagnosis sepsis. }\end{array}$ \\
\hline Altmann [48] & Prospective observational & $\begin{array}{l}\text { Septic shock }(n=16) \text {, severe } \\
\text { sepsis }(n=7), \text { SIRS }(n=10)\end{array}$ & ROTEM & $\begin{array}{l}0,12,24,48 \mathrm{~h} \text { after } \\
\text { inclusion }\end{array}$ & None & All parameters within reference values. \\
\hline Durila [49] & Prospective observational & Severe sepsis $(n=44)$ & TEG & Not stated & $\begin{array}{l}\text { INR, APTT, fibrinogen, } \\
\text { AT }\end{array}$ & All parameters within reference values. \\
\hline Adamzik [9] & Prospective observational & Sepsis $(n=98)$ & ROTEM & $\begin{array}{l}\text { Within } 24 \text { hours of } \\
\text { diagnosis }\end{array}$ & INR & $\begin{array}{l}39 \% \text { of sepsis patients had normal CFT, MCF, and a } \\
\text { angle, values in } 61 \% \text { with pathologic variable } \\
\text { showed broad distribution Hypocoagulable profile } \\
\text { associated with increased mortality (OR 4.1; } 95 \% \\
\text { CI 1.4-11.9). }\end{array}$ \\
\hline $\begin{array}{l}\text { Cortegiani } \\
\text { (abstract) [51] }\end{array}$ & Prospective observational & $\begin{array}{l}\text { Severe sepsis }(n=31) \\
\text { postoperative }(n=31)\end{array}$ & TEG & $\begin{array}{l}\text { Within } 12 \text { hours of } \\
\text { diagnosis }\end{array}$ & None & $\begin{array}{l}\text { Sepsis patients had lower a angle, other TEG } \\
\text { parameters did not differ. }\end{array}$ \\
\hline
\end{tabular}


Table 2 Studies assessing TEG/ROTEM in sepsis (Continued)

\begin{tabular}{|c|c|c|c|c|c|c|}
\hline Brenner [54] & Prospective observational & $\begin{array}{l}\text { Septic shock }(n=30) \text {, major } \\
\text { surgery }(n=30) \text {, healthy } \\
\text { volunteers }(n=30)\end{array}$ & ROTEM & $\begin{array}{l}\text { Sepsis: at diagnosis, } \\
24 \mathrm{~h}, 4,7,14,28 \text { days }\end{array}$ & $\begin{array}{l}\text { Prothrombin index, } \\
\text { factor levels, IL-6, TNF-a }\end{array}$ & $\begin{array}{l}\text { In sepsis patients, majority of ROTEM analysis within } \\
\text { reference values; however, sepsis patients with DIC } \\
\text { showed more hypocoagulable traces compared with } \\
\text { those without DIC were more hypercoagulable } \\
\text { Compared with surgical and healthy controls } \\
\text { fibrinolysis was impaired in sepsis patients. }\end{array}$ \\
\hline Durila [53] & Prospective observational & $\begin{array}{l}\text { Postsurgical esophagectomy } \\
(\mathrm{n}=38) \text {, of these, nine } \\
\text { developed sepsis. }\end{array}$ & TEG & $\begin{array}{l}\text { Morning of surgery and } \\
\text { daily day } 1-6 \text { post } \\
\text { operative }\end{array}$ & $\begin{array}{l}\text { APTT, INR, CRP, lactate, } \\
\text { IL-6, procalcitonin, AT, } \\
\text { D-dimer }\end{array}$ & $\begin{array}{l}\text { On postoperative day 6, sepsis patients had higher } \\
\text { lysis index compared with SIRS patients. Overall TEG } \\
\text { not helpful in discriminating sepsis from SIRS }\end{array}$ \\
\hline Massion [52] & Prospective cohort & Septic shock $(n=39)$ & ROTEM & Admission to day 7 & $\begin{array}{l}\text { APTT, PT, Thrombin } \\
\text { generation, factor levels, } \\
\text { AT, protein C }\end{array}$ & $\begin{array}{l}\text { Fibrinolysis was decreased (increased lysis indexes), } \\
\text { associated with hypocoagulation in conventional } \\
\text { coagulation tests (decreased protein C and AT). Other } \\
\text { parameters within reference values (CT, MCF and } \\
\text { alpha). Nonsurvivors were more hypocoagulable, } \\
\text { but ROTEM values were not independently associated } \\
\text { with mortality }\end{array}$ \\
\hline Ostrowski [10] & Prospective observational & $\begin{array}{l}\text { Severe sepsis }(N=13) \text { and } \\
\text { septic shock }(N=37)\end{array}$ & TEG & Day 1-4 & $\begin{array}{l}\text { ISTH DIC score, INR, } \\
\text { APTT, D-dimer, } \\
\text { fibrinogen, CRP }\end{array}$ & $\begin{array}{l}\text { According to cloth strength (MA), } 48 \% \text { of sepsis } \\
\text { patients was normocoagulable, } 22 \% \\
\text { hypocoagulable and } 30 \% \text { hypercoagulable. } \\
50 \% \text { of patients with hypocoagulable profile had } \\
\text { overt DIC, versus none of those with a } \\
\text { hypercoagulable profile. Hypocoagulable profile } \\
\text { predicts } 28 \text {-day mortality if corrected for SOFA, } \\
\text { but not if corrected for SAPS II score. }\end{array}$ \\
\hline Viljoen [42] & Not stated & $\begin{array}{l}\text { Sepsis }(n=15) \text {, trauma }(n=14) \text {, } \\
\text { surgery }(n=21) \text {, healthy } \\
\text { control }(n=23)\end{array}$ & TEG & Daily & $\begin{array}{l}\text { Plasma elastase-a } \\
\text { sub } 1 \mathrm{Pl}\end{array}$ & $\begin{array}{l}\text { Sepsis patients were hypocoagulable compared with } \\
\text { surgery patients and controls. Sepsis patients had } \\
\text { higher elastase-a sub } 1 \text { proteinase inhibitor levels } \\
\text { compared with controls, without a correlation with } \\
\text { TEG parameters. }\end{array}$ \\
\hline $\begin{array}{l}\text { Umgelter } \\
\text { (abstract) [45] }\end{array}$ & Not stated & $\begin{array}{l}\text { Sepsis }(n=21) \text {, no sepsis } \\
(n=23)\end{array}$ & ROTEM & Not stated & $\begin{array}{l}\text { Thrombin time, } \\
\text { D-dimer, AT }\end{array}$ & $\begin{array}{l}\text { ROTEM did not discriminate between septic and } \\
\text { nonseptic cirrhosis patients }\end{array}$ \\
\hline
\end{tabular}




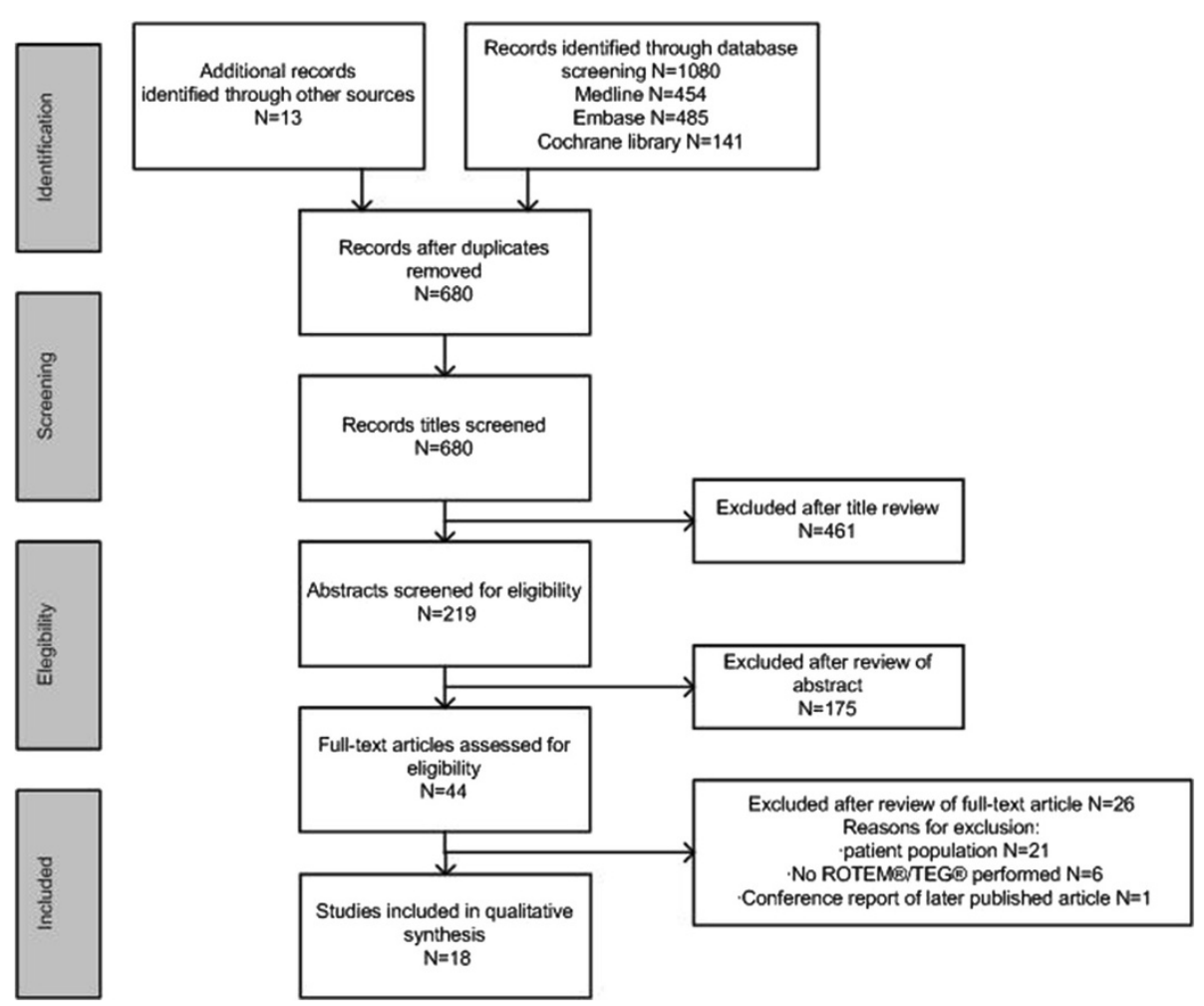

Figure 2 PRISMA flow diagram.

abstracts and trial results had been published. None had been published at December 31, 2012. Construction of a funnel plot was not feasible because of characteristics of retrieved studies.

\section{Synthesis of results}

Studies varied widely in the way they were conducted. Main differences were timing of TEG/ROTEM measurements, number of measurements, use of preset reference values or control group to assess derangements in TEG/ ROTEM measurements in sepsis, and variable use of different comparison tests. Because of this clinically relevant heterogeneity, we carried out a narrative synthesis of the results of the included studies.

\section{Ability of TEG/ROTEM to detect sepsis-induced coagulopathy}

In five studies, all TEG/ROTEM measurements in sepsis were within reference values $[44,46,48,49,54]$. These studies included a total of 176 sepsis and severe sepsis patients. In seven studies, TEG/ROTEM revealed pathologic changes ranging from distinct hypercoagulability [40] to predominantly hypocoagulable profiles [42,51]. Four prospective observational studies, together including 214 patients, reported heterogeneous results with patients showing hyper- and hypocoagulability $[9,10,41,43]$. Impaired fibrinolysis in sepsis patients was demonstrated in five different observational studies, with a total of 162 patients [41,50,52-54]. Two of these studies reported increased lysis indices as the only abnormal ROTEM parameter in 30 and 39 patients with septic shock $[52,54]$. In a small cohort of 16 patients with severe sepsis; patients were randomized to tight glycemic control or conventional glucose levels; strict regulation of glucose levels resulted in enhancement of fibrinolysis, as measured by lysis index with ROTEM [39].

Overall, if sepsis-induced coagulopathy was detected, the proportion of sepsis patients with sepsis-induced coagulopathy that was detected by TEG/ROTEM ranged from $43 \%$ to $100 \%[9,10,40,41]$.

Altogether, in the majority of studies, TEG/ROTEM was able to detect sepsis-induced coagulopathy. However, changes in parameters were heterogeneous, and study designs varied widely, with a lack of clarity in interpretation of test results. Based on this, the quality of evidence supporting the use of TEG/ROTEM to detect sepsis-induced coagulopathy is considered low.

\section{Additional value of TEG/ROTEM in sepsis compared with standard coagulation tests}

Studies designed to compare conventional coagulation tests directly with TEG/ROTEM for the detection of sepsis-induced coagulopathy were not retrieved.

However, two studies assessed the value of thromboelastography in the detection of DIC. A prospective pilot 
Table 3 Summary of risk of bias and applicability concerns for included studies

\begin{tabular}{|c|c|c|c|c|c|c|}
\hline \multirow[t]{2}{*}{ Study } & \multicolumn{3}{|c|}{ Risk of bias } & \multicolumn{3}{|c|}{ Applicability concerns } \\
\hline & $\begin{array}{l}\text { Patient } \\
\text { selection }\end{array}$ & $\begin{array}{l}\text { Conduction and } \\
\text { interpretation of } \\
\text { TEG/ROTEM }\end{array}$ & $\begin{array}{l}\text { Use and interpretation } \\
\text { of reference standard }\end{array}$ & Patient flow & Patient selection & $\begin{array}{l}\text { Reference } \\
\text { standard }\end{array}$ \\
\hline Gonano et al. [40] & - & $?$ & - & $?$ & - & - \\
\hline Raineri et al. [39] & $?$ & $?$ & - & - & - & - \\
\hline Collins et al. [43] & $?$ & $?$ & - & $?$ & - & - \\
\hline Chiari et al. [47] & - & $?$ & - & $?$ & - & - \\
\hline Daudel et al. [44] & - & - & - & $?$ & - & - \\
\hline Schmittinger et al. [46] & - & - & NA & - & - & NA \\
\hline Sivula et al. [41] & - & $?$ & $?$ & $?$ & - & - \\
\hline Adamzik et al. [50] & - & $?$ & $?$ & - & - & - \\
\hline Altmann et al. [48] & - & $?$ & NA & NA & - & NA \\
\hline Durila et al. [49] & - & + & - & - & - & - \\
\hline Adamzik et al. [9] & - & - & - & + & - & - \\
\hline Cortegiani et al. [51] & $?$ & $?$ & NA & - & - & NA \\
\hline Brenner et al. [54] & - & - & - & - & - & - \\
\hline Durila et al. [53] & - & $?$ & $?$ & + & - & - \\
\hline Massion et al. [52] & - & $?$ & - & - & - & - \\
\hline Ostrowski et al. [10] & - & - & - & + & - & - \\
\hline Viljoen et al. [42] & + & $?$ & $?$ & $?$ & + & + \\
\hline Umgelter et al. [45] & + & + & NA & $?$ & + & NA \\
\hline
\end{tabular}

-, low risk; +, high risk; ?, unclear risk; NA, not applicable.

study in 28 sepsis patients showed that CFT, MCF, and $\alpha$ angle discriminated moderately between overt DIC and no DIC. ROC values were 0.815 (CI, 0.624 to 0.935 ) for CFT, 0.891 (CI, 0.715 to 0.975 ) for MCF, and 0.828 (CI, 0.639 to 0.943 ) for $\alpha$ angle. Combination of CFT, MCF, and $\alpha$ resulted in a sensitivity of $100 \%$ and a specificity of $75 \%$, with a positive likelihood ratio of 4.0 and negative likelihood ratio of 0.0 for the diagnosis of DIC [41].

A recent study showed that ROTEM values were within reference values. However, patients with overt DIC had prolonged CFT and reduced MCF compared with those without DIC. ROC curves for MCF in EXTEM (0.806; sensitivity, 79\%; specificity, 75\%) and MCF in INTEM (0.853; sensitivity, 86\%; and specificity, 81\%) achieved fairly good results [54].

Interestingly, TEG/ROTEM failed to detect coagulopathy in two observational studies, whereas conventional coagulation assays were outside normal ranges [44,49]. In 44 sepsis patients, mean INR, D-dimer, and fibrinogen levels were increased, whereas mean TEG values were not [49]. A study of 30 sepsis patients revealed similar results, with decreased levels of individual factor levels and increased APTT tests, whereas ROTEM variables remained within reference values [44].

Some studies addressed the question whether TEG/ ROTEM was superior in discriminating sepsis from nonsepsis patients compared with conventional biomarkers. Indeed, two observational studies demonstrated that the lysis index derived from thromboelastometry could be helpful to discriminate between sepsis and postoperative inflammatory response [50,54]. Decreased fibrinolytic activity, as reflected by the lysis index, was found to discriminate sepsis from postoperative SIRS patients (ROC-AUC, 0.811; sensitivity, 93\%; specificity, $50 \%$ ), which was comparable to CRP and procalcitonin [54]. In a larger cohort of 56 sepsis patients and 52 postoperative controls, lysis index had even better diagnostic value than did procalcitonin (ROC-AUC, 0.901; sensitivity, 84\%; and specificity, 94\%) [50]. In contrast, in cirrhosis patients and postesophagectomy patients, thromboelastometry variables failed to discriminate between sepsis and nonsepsis patients $[45,53]$.

Ability of TEG/ROTEM to identify patients likely to benefit from anticoagulant treatment in sepsis

We hypothesized that TEG/ROTEM might help to identify patients likely to respond to therapies that target coagulopathy. However, we did not find any study addressing this question. The only data on TEG/ROTEM and therapy interfering with coagulation consist of a few small patient series evaluating TEG/ROTEM measurements during anticoagulant treatment. In an observational study of 
15 patients treated with rhAPC, ROTEM measurements did not change during treatment [47]. Gonano [40] showed distinct hypercoagulability in 33 patients with severe sepsis, of whom 17 were treated with antithrombin. In these patients, hypercoagulability was not reversed by the treatment.

\section{Use of TEG/ROTEM in prognostication of outcome}

Although initially not looked for, we extracted a limited number of studies that addressed the value of TEG/ ROTEM in predicting outcome in sepsis and decided post hoc to add these data to the review. In a cohort of 98 sepsis patients, by using multivariate analysis, a hypocoagulable profile on admission was shown to be an independent risk factor for 30-day mortality (OR, 4.1; 95\% CI, 1.4 to 11.9) [9]. However, not all studies have unequivocally showed the prognostic value of hypocoagulability with mortality after correcting for disease severity $[10,52]$.

In 50 patients with severe sepsis, hypocoagulable TEG MA at admission was an independent predictor for 28-day mortality in a multivariate model including SOFA score (hazard ratio, 4.29 (1.35 to 13.65 ); $P=$ 0.014 ), but not in a model using SAPS II score (hazard ratio, 2.32 (0.66 to 8.15); $P=0.188$ ) [10]. Of note, in a multivariate model a hypocoagulable profile due to a persistent deficit in thrombin generation was a strong predictor of hospital mortality $(P=0.024)$, as was APTT $(P=0.007)[52]$. The presence of hypercoagulability did not predict outcome.

Quality of evidence of studies addressing the value of TEG/ROTEM to predict mortality is considered of moderate quality. Of note, in these studies, most patients had thromboelastography values outside reference ranges.

\section{Discussion}

This systematic review on studies performing TEG/ ROTEM measurements in sepsis patients shows that studies were heterogeneous in design, use of control groups, timing of TEG/ROTEM measurements, and chosen end points. Internal validity of most studies is limited. Although most studies included sepsis patients according to the ACCM/SCCP definition, external validity is limited because of relatively small patient groups in most studies. Furthermore, standardization of used tests is limited, and most studies had methodologic flaws, which may have resulted in bias. Thereby, the overall quality of evidence on the value of TEG/ROTEM in adults with sepsis is considered low.

Results of TEG/ROTEM measurements in sepsis vary widely across studies and show both hypo- and hypercoagulability [10,40-43,46,51]. This is consistent with the pathophysiology of "consumption coagulopathy" during DIC, in which microvascular thrombi are formed at the expense of a bleeding tendency because of low levels of platelets and coagulation factors [56]. Of note, heterogeneity of results can also be caused by differences in disease severity, as changes were more obvious in severe sepsis patients $[40,41,46,51]$ than in sepsis patients. In addition, variation in the way studies were conducted has probably contributed to differences in outcome.

Interestingly, the degree of hypocoagulation was found to be associated with severity of organ failure [44]. In a study comparing different patient populations, hypocoagulation measured with TEG was most apparent in sepsis patients and associated with a proinflammatory response and organ failure [42]. Timing of measurements may be relevant to these observations, as hypocoagulation was found to be more obvious in the acute phase of sepsis and returned to normal values toward discharge from the ICU $[44,51]$.

Included studies varied widely with regard to the detection of hypercoagulability, ranging from $30 \%$ [10] to $100 \%$ [40], which may have resulted from variation in timing as well as in the definition of hypercoagulability. Of note, TEG/ROTEM clearly demonstrated hypercoagulability in models of endotoxemia [57], with a strong correlation with plasma levels of prothrombin fragments $\mathrm{F} 1+2[58,59]$.

In addition to hypo- and hypercoagulability, TEG/ROTEM can detect impairment in fibrinolysis, expressed as increased lysis indices. Hypofibrinolysis has been demonstrated in several studies in sepsis patients [41,50,52-54], but the clinical relevance of this finding must be determined. Of note, increased lysis indices were shown to be helpful in discriminating sepsis and SIRS patients [50,53,54].

TEG/ROTEM has been shown to be promising in diagnosing DIC, and in particular, the combination of various parameters (reaction times, maximum amplitude, and $\alpha$ angle) improves diagnostic value [41,54]. A score to detect DIC with the use of thromboelastometry has been developed, including prolonged reaction and $K$ times and decreased $\alpha$ angle and maximum amplitude. This score was validated in patients with an underlying disease known to be associated with DIC and with an ISTH DIC [60] score of more than 5. However, to date, this score has not been validated in critically ill patients with sepsis, and included studies in this review consisted of relatively small patient groups. Therefore to date, quality of evidence supporting the use of TEG/ROTEM to diagnose DIC is low, and further research is necessary.

Several factors in the way TEG/ROTEM measurements were conducted may have affected the results of included studies. First, coagulopathy in sepsis is a dynamic process, evolving from subtle activation of coagulation to overt DIC. Therefore, timing may greatly influence TEG/ROTEM results. Performing sequential measurements will probably provide better insight into the development of coagulation derangements. Timing 
and number of measurements in included studies varied widely.

Second, no uniform definitions exist of hypo- and hypercoagulability. Reference values for patients with sepsis are not widely assessed, and only one study determined cut-off values for a cohort of sepsis patients [9]. Some studies classified patients as hypo- or hypercoagulable when measurements were outside preset reference ranges $[10,40,44,46]$; others compared patients with healthy individuals [41,43,50,52,54]; and some compared mean or median values among or within different patient groups $[9,39,42,45-51,53,54]$. To compare patient categories and possibly investigate therapeutic interventions in the coagulation system, validated universal reference values and definitions are essential. For ROTEM, a multicenter investigation has been undertaken to assess reference values [4]. A study to verify reference intervals of TEG reagents was recently completed (NCT01357928), and we hope that results will contribute to further standardization of TEG.

Third, the included studies differed in the types of reagents used, which may have considerable effects on the results of the studies. Most studies using ROTEM used tissue factor, after recalcification of the citrated sample, to enhance coagulation $[41,43,44,48,52,54]$, although some also performed a nonactivated test (NATEM). Of the studies using TEG, only one study reported the use of kaolin activation [49]; the others only recalcified samples before testing. Of note, correlation between non-kaolinactivated and kaolin-activated thromboelastography has shown to be poor [61]. Furthermore, in some studies, a potential heparin effect was blocked by the addition of heparinase $[9,40,44,50,52,54]$, whereas others lacked information on the use of heparinase $[10,42]$.

In the current review, we included studies using ROTEM and studies using TEG. None of the included studies studied both devices. Some studies that compared both devices in other patient populations showed differences in test results between ROTEM and TEG $[62,63]$, although not all [64]. Therefore, comparisons of results of studies using different devices should be made cautiously.

A hypocoagulable profile detected by TEG/ROTEM seems to be associated with increased mortality among sepsis patients $[9,10,46]$. One could argue that a hypocoagulable profile merely reflects severity of disease. However, in the study of Adamzik [9], hypocoagulable TEG/ROTEM remained an independent predictor of mortality after correction for severity of disease. These findings are in line with results in a larger cohort of general intensive care patients, in which a hypocoagulable profile at admission was associated with an increased mortality [26]. This relation questions the role of coagulation in inflammatory processes. We speculate that enhanced coagulation during infection is functional, thereby preventing dissemination of bacteria. Thereby, hypocoagulability may facilitate enhanced spread of infection and subsequently mortality [65]. The finding that hypocoagulability is associated with organ failure and is an independent risk factor for mortality underlines the need for further research. Currently, two observational prospective trials in sepsis patients are being conducted (NCT00994877 and NCT00299949) on the value of TEG/ROTEM to diagnose DIC and to predict organ failure in sepsis. Results of these studies may help to determine whether TEG/ROTEM can be used to select specific patient populations who are likely to benefit from therapies aimed at intervention in the coagulation cascade during sepsis.

Our review has limitations, which include the lack of a uniform definition of hypo- and hypercoagulability assessed by ROTEM or TEG, different reference values, differences in control groups, and the heterogeneous study quality. Another limitation is related to our search, in which we may have missed studies published in languages other than English, as well as unpublished data. In addition, we might have missed studies because of the applied date restriction and limitation of our search to three databases.

\section{Conclusion}

A considerable proportion of sepsis patients have an altered coagulation status. An abnormal TEG/ROTEM, in particular hypocoagulability, is prognostic for mortality in the critically ill. Also, hypocoagulability as detected by TEG/ROTEM may aid in diagnosing DIC and hypofibrinolysis. Despite heterogeneity and the limited quality of most included studies, application of TEG/ROTEM seems a promising tool in sepsis. However, given that coagulopathy is a dynamic process, more insight into the kinetics of the coagulation alterations, as diagnosed by TEG/ROTEM, is needed before the general use of TEG/ROTEM to detect hyper- or hypocoagulability and DIC can be advocated.

\section{Key messages}

- Current studies on TEG/ROTEM in patients with sepsis are of heterogeneous quality, but TEG/ ROTEM could be a promising tool in diagnosing alterations in coagulation in sepsis.

- Hypocoagulability, as detected by TEG/ROTEM, may aid in diagnosing disseminated intravascular coagulation.

- An abnormal TEG/ROTEM, in particular, a hypocoagulable profile, is prognostic for mortality in the critically ill.

- Further research on the value of TEG/ROTEM in sepsis is warranted, and sequential measurements are needed to understand the coagulation patterns, as can be detected by TEG/ROTEM. 


\section{Abbreviations}

APTT: Activated partial thromboplastin time; AT: antithrombin; AUC: area under the curve; CFT: clot-formation time; CT: clotting time; DIC: disseminated intravascular coagulation; ICU: intensive care unit; INR: International Normalized Ratio; ISTH: International Society on Thrombosis and Hemostasis; MA: maximal amplitude; MCF: maximal clot firmness; MOF: multiple organ failure; PAI-1: plasminogen activator inhibitor-1; PT: prothrombin time; rhAPC: recombinant activated protein C; ROC: receiver operating characteristic curve; SIRS: systemic inflammatory response SOFA: Sequential Organ Failure Assessment Score; TFPI: tissue factor pathway inhibitor.

\section{Competing interests}

MCM, JCM, and MBV have no competing interests to declare. NPJ received a grant from the manufacturer on the utility of TEG in diagnosing traumatic coagulopathy.

\section{Authors' contributions}

MCM and NPJ performed the literature search and selected the relevant articles for inclusion independently. MCM and NPJ reviewed the selected articles and wrote the initial draft of the manuscript. JCM and MBV critically revised the manuscript. All authors read and approved the manuscript for publication.

\section{Author details}

'Department of Intensive Care Medicine and Laboratory of Experimental Intensive Care and Anesthesiology (L.E.I.C.A.), Academic Medical Center, Room G3-220, Meibergdreef 9, 1105AZ, Amsterdam, The Netherlands. 2Departments of Experimental Vascular Medicine and Vascular Medicine, Academic Medical Center, Amsterdam, The Netherlands.

Received: 8 May 2013 Accepted: 29 January 2014

Published: 10 February 2014

\section{References}

1. Walsh TS, Stanworth SJ, Prescott RJ, Lee RJ, Watson DM, Wyncoll D: Prevalence, management, and outcomes of critically ill patients with prothrombin time prolongation in United Kingdom intensive care units. Crit Care Med 2010, 38:1939-1946.

2. Levi M, Meijers JC: DIC: which laboratory tests are most useful. Blood Rev 2011, 25:33-37.

3. Reikvam H, Steien E, Hauge B, Liseth $K$, Hagen KG, Storkson R, Hervig T: Thrombelastography. Transfus Apher Sci 2009, 40:119-123.

4. Lang T, Bauters A, Braun SL, Potzsch B, von Pape KW, Kolde HJ, Lakner M: Multi-centre investigation on reference ranges for ROTEM thromboelastometry. Blood Coagul Fibrinol 2005, 16:301-310.

5. Abraham E, Reinhart K, Opal S, Demeyer I, Doig C, Rodriguez AL, Beale R, Svoboda P, Laterre PF, Simon S, Light B, Spapen H, Stone J, Seibert A, Peckelsen C, De DC, Postier R, Pettila V, Artigas A, Percell SR, Shu V, Zwingelstein C, Tobias J, Poole L, Stolzenbach JC, Creasey AA: Efficacy and safety of tifacogin (recombinant tissue factor pathway inhibitor) in severe sepsis: a randomized controlled trial. JAMA 2003, 290:238-247.

6. Afshari A, Wetterslev J, Brok J, Moller A: Antithrombin III in critically ill patients: systematic review with meta-analysis and trial sequential analysis. BMJ 2007, 335:1248-1251.

7. Bernard GR, Vincent JL, Laterre PF, LaRosa SP, Dhainaut JF, Lopez-Rodriquez A, Steingrub JS, Garber GE, Helterbrand JD, Ely EW, Fisher CJ Jr: Efficacy and safety of recombinant human activated protein $C$ for severe sepsis. N Engl J Med 2001, 344:699-709.

8. Jaimes F, De La Rosa G, Morales C, Fortich F, Arango C, Aguirre D, Munoz A: Unfractioned heparin for treatment of sepsis: a randomized clinical trial (The HETRASE Study). Crit Care Med 2009, 37:1185-1196.

9. Adamzik M, Langemeier T, Frey UH, Gorlinger K, Saner F, Eggebrecht $H$, Peters J, Hartmann M: Comparison of thrombelastometry with simplified acute physiology score II and sequential organ failure assessment scores for the prediction of 30-day survival: a cohort study. Shock 2011, 35:339-342.

10. Ostrowski SR, Windelov NA, Ibsen M, Haase N, Perner A, Johansson PI: Consecutive thrombelastography clot strength profiles in patients with severe sepsis and their association with 28-day mortality: a prospective study. J Crit Care 2013, 28:317.
11. Whiting PF, Rutjes AW, Westwood ME, Mallett S, Deeks JJ, Reitsma JB, Leeflang MM, Sterne JA, Bossuyt PM: QUADAS-2: a revised tool for the quality assessment of diagnostic accuracy studies. Ann Intern Med 2011, 155:529-536.

12. A quality assessment tool for diagnostic accuracy studies: QUADAS-2: Background document. via http://www.bris.ac.uk/quadas/quadas-2/. accessed 5 June 2013.

13. Hasegawa $\mathrm{H}$ : Estimation of coagulation-fibrinolytic factors in DIC. Bib/ Haematol 1983, 49:173-180

14. Clayton DG, Miro AM, Kramer DJ, Rodman N, Wearden S: Quantification of thrombelastographic changes after blood component transfusion in patients with liver disease in the intensive care unit. Anesth Analg 1995, 81:272-278

15. Mohri M, Suzuki M, Sugimoto E, Sata M, Yamamoto S, Maruyama I: Effects of recombinant human soluble thrombomodulin (rhs-TM) on clot-induced coagulation in human plasma. Thromb Haemost 1998, 80:925-929.

16. Baldwin I, Tan HK, Bridge N, Bellomo R: A prospective study of thromboelastography (TEG) and filter life during continuous veno-venous hemofiltration. Ren Fail 2000, 22:297-306.

17. Doria C, Mandala L, Smith JD, Caruana G, Scott VL, Gruttadauria S, Magnone M, Marino IR: Thromboelastography used to assess coagulation during treatment with molecular adsorbent recirculating system. Clin Transplant 2004, 18:365-371.

18. Dunser MW, Fries DR, Schobersberger W, Ulmer H, Wenzel V, Friesenecker B, Hasibeder WR, Mayr AJ: Does arginine vasopressin influence the coagulation system in advanced vasodilatory shock with severe multiorgan dysfunction syndrome? Anesth Analg 2004, 99:201-206.

19. King DR, Cohn SM, Feinstein AJ, Proctor KG: Systemic coagulation changes caused by pulmonary artery catheters: laboratory findings and clinical correlation. J Trauma 2005, 59:853-857.

20. Faybik P, Bacher A, Kozek-Langenecker SA, Steltzer H, Krenn CG, Unger S Hetz H: Molecular adsorbent recirculating system and hemostasis in patients at high risk of bleeding: an observational study. Crit Care 2006, 10:R24.

21. Nilsson CU, Hellkvist PD, Engstrom M: Effects of recombinant human activated protein $\mathrm{C}$ on the coagulation system: a study with rotational thromboelastometry. Acta Anaesthesio/ Scand 2008, 52:1246-1249.

22. Van PY, Cho SD, Underwood SJ, Morris MS, Watters JM, Schreiber MA: Thrombelastography versus AntiFactor Xa levels in the assessment of prophylactic-dose enoxaparin in critically ill patients. J Trauma 2009, 66:1509-1515.

23. Mineo G, Cascio ND, Canzio D, Marino L, Evangelico G, Cortegiani A, Raineri SM: Fondaparinux vs low molecular weight heparin as a thromboprophylaxis in critically ill patients: coagulation status monitored by thromboelastography [abstract]. Intensive Care Med 2009, Conference:S217.

24. Sharma P, Saxena R: A novel thromboelastographic score to identify overt disseminated intravascular coagulation resulting in a hypocoagulable state. Am J Clin Pathol 2010, 134:97-102.

25. White $\mathrm{H}$, Zollinger $\mathrm{C}$, Jones M, Bird R: Can thromboelastography performed on kaolin-activated citrated samples from critically ill patients provide stable and consistent parameters? Int J Lab Hematol 2010, 32:167-173

26. Johansson Pl, Stensballe J, Vindelov N, Perner A, Espersen K Hypocoagulability, as evaluated by thrombelastography, at admission to the ICU is associated with increased 30-day mortality. Blood Coagul Fibrinol 2010, 21:168-174

27. Dimitrova-Karamfilova A: Thromboelastometry for the assessment of hypercoagulation in critically ill cardiac patients [abstract]. Transfusion Altern Transfus Med 2010, Conference:37.

28. Stravitz RT, Lisman T, Luketic VA, Sterling RK, Puri P, Fuchs M, Ibrahim A, Lee WM, Sanyal AJ: Minimal effects of acute liver injury/acute liver failure on hemostasis as assessed by thromboelastography. J Hepatol 2012, 56:129-136.

29. Agarwal B, Wright G, Gatt A, Riddell A, Vemala V, Mallett S, Chowdary P, Davenport A, Jalan R, Burroughs A: Evaluation of coagulation abnormalities in acute liver failure. J Hepatol 2012, 57:780-786.

30. Ryan ML, Thorson CM, King DR, Van Haren RM, Manning RJ, Andrews DM, Livingstone AS, Proctor KG: Insertion of central venous catheters induces a hypercoagulable state. J Trauma Acute Care Surg 2012, 73:385-390.

31. Wada H, Sakakura M, Kushiya F, Nisikawa M, Onishi K, Nakatani K, Shiku H, Nobori T: Thrombomodulin accelerates activated protein $\mathrm{C}$ production 
and inhibits thrombin generation in the plasma of disseminated intravascular coagulation patients. Blood Coagul Fibrinol 2005, 16:17-24

32. Picoli-Quaino SK, Alves BE, Aranha FJP, Lorand-Metze I, De Souza CA Annichino-Bizzacchi JM, De Paula EV: Evaluation of thrombin generation in the early stages of sepsis in patients with hematological malignancies and febrile neutropenia [abstract]. ASH Conference Proceedings 2011 Conference:3347.

33. Soshitova NP, Karamzin SS, Balandina AN, Fadeeva OA, Kretchetova AV Galstian GM, Panteleev MA, Ataullakhanov FI: Predicting prothrombotic tendencies in sepsis using spatial clot growth dynamics. Blood Coagul Fibrinol 2012, 23:498-507.

34. Baudo F, Caimi TM, DeCataldo F, Ravizza A, Arlati S, Casella G, Carugo D, Palareti G, Legnani C, Ridolfi L, Rossi R, D'Angelo A, Crippa L, Giudici D, Gallioli G, Wolfler A, Calori G: Antithrombin III (ATIII)) replacement therapy in patients with sepsis and/or postsurgical complications: a controlled double-blind, randomized, multicenter study. Intensive Care Med 1998, 24:336-342.

35. Galstyan GM, Krechetova AV, Alexanyan MG, Sinauridze El, Gorodetsky VM, Vasiliev SA: Thrombin generation in patients (pts) with severe sepsis and septic shock during the treatment with high doses of antithrombin (AT) [abstract]. J Thromb Haemost 2009, Conference:684.

36. Tsen A, Kirschenbaum LA, Larow C, Khan R, Kurtz S, Bansal S, Astiz ME: The effect of anticoagulants and the role of thrombin on neutrophilendothelial cell interactions in septic SHOCK. Shock 2009, 31:120-124.

37. Ogawa Y, Yamakawa K, Ogura H, Kiguchi T, Mohri T, Nakamori Y, Kuwagata Y, Shimazu T, Hamasaki T, Fujimi S: Recombinant human soluble thrombomodulin improves mortality and respiratory dysfunction in patients with severe sepsis. J Trauma 2011, 72:1150-1157.

38. Durila M, Bronsky J, Harustiak T, Pazdro A, Pechova M, Cvachovec K: Biochemical and hematological parameters (including thromboelastography) differ in patients with sepsis and SIRS after esophagectomy. Crit Care 2011, 15:443.

39. Raineri SM, Cangemi L, Cortegiani A, Cascio ND, Mineo G, Evangelico G, Giarratano A: Fibrinolysis system, monitored by thromboelastography (TEG) and PAI-1 activity, in septic patients undergoing tight glycemic control [abstract]. Intensive Care Med 2009, Conference:S162.

40. Gonano C, Sitzwohl C, Meitner E, Weinstabl C, Kettner SC: Four-day antithrombin therapy does not seem to attenuate hypercoagulability in patients suffering from sepsis. Crit Care 2006, 10:R160.

41. Sivula $M$, Pettila $V$, Niemi $\Pi$, Varpula $M$, Kuitunen $A H$ : Thromboelastometry in patients with severe sepsis and disseminated intravascular coagulation. Blood Coagul Fibrinol 2009, 20:419-426.

42. Viljoen M, Roux LJ, Pretorius JP, Coetzee IH, Viljoen E: Hemostatic competency and elastase-alpha 1-proteinase inhibitor levels in surgery, trauma, and sepsis. J Trauma 1995, 39:381-385.

43. Collins PW, Macchiavello LI, Lewis SJ, Macartney NJ, Saayman AG, Luddington R, Baglin T, Findlay GP: Global tests of haemostasis in critically ill patients with severe sepsis syndrome compared to controls. $\mathrm{Br} J$ Haematol 2006, 135:220-227.

44. Daudel F, Kessler U, Folly H, Lienert JS, Takala J, Jakob SM: Thromboelastometry for the assessment of coagulation abnormalities in early and established adult sepsis: a prospective cohort study. Crit Care 2009, 13:R42.

45. Umgelter A, Msmer G, Schmid RM, Kreymann B: Thromboelastography and platelet function assay in cirrhosis and sepsis [abstract]. Intensive Care Med 2009, Conference:S160.

46. Schmittinger CA, Dunser MW, Torgersen C, Hasibeder WR, Luckner G, Mayr $V$, Jochberger S: Rotational thromboelastometry to assess the coagulation system in severe sepsis and the systemic inflammatory response syndrome: a prospective, controlled trial [abstract]. Intensive Care Med 2009, Conference:S162.

47. Chiairi F, Ickx B, Barvais L, Vincent J-L, Piagnerelli M: Does activated protein $C$ influence the coagulation system assessed by the rotative thromboelastometry analysis [abstract]. Intensive Care Med 2009, Conference:S162.

48. Altmann DR, Korte W, Maeder MT, Fehr T, Haager P, Rickli H, Kleger GR, Rodriguez R, Ammann P: Elevated cardiac troponin I in sepsis and septic shock: no evidence for thrombus associated myocardial necrosis. Plos One 2010, 5:e9017.

49. Durila M, Kalincik T, Jurcenko S, Pelichovska M, Hadacova I, Cvachovec K: Arteriovenous differences of hematological and coagulation parameters in patients with sepsis. Blood Coagul Fibrinol 2010, 21:770-774.

50. Adamzik M, Eggmann M, Frey UH, Gorlinger K, Brocker-Preuss M, Marggraf G, Saner F, Eggebrecht H, Peters J, Hartmann M: Comparison of thromboelastometry with procalcitonin, interleukin 6, and C-reactive protein as diagnostic tests for severe sepsis in critically ill adults. Crit Care 2010, 14: R178.

51. Cortegiani A, Marino L, Montalto F, Milana M, Di Benedetto A, Vento L, et al: Use of thromboelastography in severe sepsis: a case-control study [abstract]. Crit Care 2011, 15:444.

52. Massion PB, Peters P, Ledoux D, Zimermann V, Canivet JL, Massion PP, Damas $P$, Gothot A: Persistent hypocoagulability in patients with septic shock predicts greater hospital mortality: impact of impaired thrombin generation. Intensive Care Med 2012, 38:1326-1335.

53. Durila M, Bronsky J, Harustiak T, Pazdro A, Pechova M, Cvachovec K: Early diagnostic markers of sepsis after oesophagectomy (including thromboelastography). BMC Anesthesio/ 2012, 12:12.

54. Brenner T, Schmidt K, Delang M, Mehrabi A, Bruckner T, Lichtenstern C, Martin E, Weigand MA, Hofer S: Viscoelastic and aggregometric point-of-care testing in patients with septic shock: cross-links between inflammation and haemostasis. Acta Anaesthesiol Scand 2012, 56:1277-1290.

55. Bone RC, Balk RA, Cerra FB, Dellinger RP, Fein AM, Knaus WA, Schein RM, Sibbald WJ: Definitions for sepsis and organ failure and guidelines for the use of innovative therapies in sepsis, The ACCP/SCCM Consensus Conference Committee, American College of Chest Physicians/Society of Critical Care Medicine. Chest 1992, 101:1644-1655.

56. Levi M, De JE, Van der Poll T: Sepsis and disseminated intravascular coagulation. J Thromb Thrombol 2003, 16:43-47.

57. Schochl H, Solomon C, Schulz A, Voelckel W, Hanke A, Van GM, Redl H, Bahrami S: Thromboelastometry (TEM) findings in disseminated intravascular coagulation in a pig model of endotoxinemia. Mol Med 2011, 17:266-272.

58. Spiel AO, Mayr FB, Firbas C, Quehenberger P, Jilma B: Validation of rotation thrombelastography in a model of systemic activation of fibrinolysis and coagulation in humans. J Thromb Haemost 2006, 4:411-416.

59. Zacharowski K, Sucker C, Zacharowski P, Hartmann M: Thrombelastography for the monitoring of lipopolysaccharide induced activation of coagulation. Thromb Haemost 2006, 95:557-561.

60. Taylor FB Jr, Toh $\mathrm{CH}$, Hoots WK, Wada H, Levi M: Towards definition, clinical and laboratory criteria, and a scoring system for disseminated intravascular coagulation. Thromb Haemost 2001, 86:1327-1330.

61. Thalheimer U, Triantos CK, Samonakis DN, Zambruni A, Senzolo M, Leandro G, Patch D, Burroughs AK: A comparison of kaolin-activated versus nonkaolin-activated thromboelastography in native and citrated blood. Blood Coagul Fibrinol 2008, 19:495-501.

62. Nielsen VG: A comparison of the Thrombelastograph and the ROTEM. Blood Coagul Fibrinol 2007, 18:247-252.

63. Solomon C, Sorensen B, Hochleitner G, Kashuk J, Ranucci M, Schochl H: Comparison of whole blood fibrin-based clot tests in thrombelastography and thromboelastometry. Anesth Analg 2012, 114:721-730.

64. Venema LF, Post WJ, Hendriks HG, Huet RC, de Wolf JT, de Vries AJ: An assessment of clinical interchangeability of TEG and RoTEM thromboelastographic variables in cardiac surgical patients. Anesth Analg 2010, 111:339-344

65. Massberg S, Grahl L, von Bruehl ML, Manukyan D, Pfeiler S, Goosmann C, Brinkmann V, Lorenz M, Bidzhekov K, Khandagale AB, Konrad I, Kennerknecht E, Reges K, Holdenrieder S, Braun S, Reinhardt C, Spannagl M, Preissner KT, Engelmann B: Reciprocal coupling of coagulation and innate immunity via neutrophil serine proteases. Nat Med 2010, 16:887-896.

doi:10.1186/cc13721

Cite this article as: Müller et al:: Utility of thromboelastography and/or thromboelastometry in adults with sepsis: a systematic review. Critical Care 2014 18:R30 